\title{
THE ATTEMPT TO REDUCE CHANGEOVER TIME USING THE SMED METHOD IN THE PRODUCTION ENTERPRISE $X$
}

\begin{abstract}
Nowadays, with global free market economy, which is characterized by strong competition and variability occurring in macro- and microenvironments, enterprises implement tools and methods that allow for collecting current and reliable data (qualitative and quantitative) concerning various parts of its functioning and, with adequate processing and presentation, indicate the areas for process improvement and waste reduction, leading to the improvement in the rate of return. One of the methods to ensure a more efficient manufacturing is SMED. With adequate implementation of the stages of this method, changeover time is minimized, thus reducing costs of production. This study presents an attempt to implement the SMED method in a selected area of production in the enterprise X.
\end{abstract}

Keywords: Lean Management, SMED, changeover

\section{Introduction}

Implementation of changes that lead to numerous improvements, waste minimization or facilitation of production is ensured by the use of lean management methods. The use of these techniques offers such benefits as reduced waste, reduced changeover time, improved efficiency of workers through adequate workplace organization. They are often defined as a general package named Lean Toolbox. The examples of its components are such tools and techniques as Just-in-Time, 5S, PokaYoke, TPM, Kanban or SMED (SZATKOWSKI K. 2014).

The SMED method allows for shortening of machine changeover time to even several minutes. More and more often, this is also applicable to large and heavy manufacturing machines. The method improves safety during changeovers and leads to higher flexibility of the production system. It is used for various pieces of equipment on production lines, machines and production processes (KOCH T. 2011). The most important assumption of the SMED method is to limit the changeover time to less than 10 minutes, with the process performed with the fewest tools possible. SMED starts from definition of the changeover time as a time from the last part of good quality from the previous batch to the first part of good quality of the next batch. SMED involves not only the activities concerning the machine changeover but also all

\footnotetext{
1 Wroclaw University of Economics, Poland, Faculty of Engineering and Economics, e-mail: aemerych@wp.pl

2 Wroclaw University of Economics, Poland, Faculty of Engineering and Economics, e-mail: szymon.dziuba@ue.wroc.pl
} 
the preparation works when the machine is stopped or works at a reduced efficiency. During the changeover, all the adjustment and cleaning works should be taken into account (COIMBRA E. A. 2009).

All the operations performed during changeovers can be divided into the two groups:

- internal changeovers,

- external changeovers.

The internal changeovers include all the activities which are performed during machine operation. The external changeovers include the works performed when the machine is turned on. The main objective of the SMED is to change all the internal components into external ones by using the SMED methodology, which describes changeover as using the five following steps (SHINGO S. 1989):

Step 1:

Examine the current situation. This stage consists in observation of the current changeover method. It is essential to use people who are usually involved in changeovers and ensure the commitment of the interdisciplinary team. The tools used at this stage are: time line analyses, video recording, spaghetti diagram, observation list and flash light list.

\section{Step 2:}

Internal activities should be separated from the external ones. In this stage, time line analysis is used to classify individual tasks as external activities which can be performed during machine operation, and the internal activities, which can be performed only when the machine is stopped. All the activities considered as external should be arranged in the beginning and at the end of the process, whereas the tasks classified as internal should be divided according to a new operating standard. Next, the operator/s should be immediately familiarized with the new standard.

\section{Step 3:}

Internal activities should be converted into external activities. Detailed analysis of the internal tasks can reveal how implementation of certain improvements can help perform some of these tasks at the outside of the changeover, i.e. before or after the machine is stopped. A classic example of such an improvement is the device which heats the die (heating of the die is performed before the changeover is started. This eliminates the time of waiting for die heating to reach the adequate temperature) 


\section{Step 4:}

Duration of internal activities should be reduced. This means application of the measures which allow for shortening of internal activities to reduce machine stoppage time.

\section{Step 5:}

Duration of external activities should be reduced. This means finding the measures that allow for performing external activities in shorter time.

Division of SMED methodology into individual stages makes work of research teams easier and substantially impacts the understanding of the idea of individual steps.

A key element of the SMED method is also to develop standards and train employees. Effective, properly developed standards and well-trained staff is able to perform fast and frequent changeovers in an easy and natural manner which reaching a good flow of materials and good machine efficiency.

\section{Study aim}

The aim of the study was to reduce changeover time using the SMED method in the department of processing in the Enterprise X. The following research methods were used to achieve the research aim:

- inductive method,

- interview,

- technical data presentation,

- other SMED-specific methods.

Examinations and data analysis in the Enterprise $\mathrm{X}$ were performed from 1 February 2016 to 31 July 2016.

\section{Choice of machine and preparation for changeover}

Varied machinery stock in the Enterprise X causes that the choice is even harder. Adequate formulation of the needs for optimization occurs based on such data as the number of changeovers a month, changeover time and the group of machines involved in the changeover. Based on the above conditions, 3 changeovers were scheduled for 2016 in the area of this process machines. The choice of the first changeover was determined by the mean number of changeovers a month and opportunities for using the results obtained from workshops concerning 8 machines. An additional advantage was the number of unwinders on this machine as the changeover is more problematic for the operators. 
Preparation for the changeover included training, observation of changeover and creation of initial standard. Then, verification of a new changeover and creation of changeover instruction was performed. These initial activities ensured implementation of consecutive stages in changeover.

\section{Team}

The team was formed by the employees of production departments and the departments cooperating with production. These were many-year and experienced employees from the Enterprise X. The tasks assigned to team members had a substantial effect on the results. The KAIZEN department assigned two coordinators to the workshop. One of the coordinators became a workshop moderators. During the workshop, one KAIZEN coordinator was involved in plotting of the spaghetti diagram. The other one recorded the order of the tasks performed. Production technician and process technologist focused on recording the video and observation of the changeover to optimize this process. Shift manager supervised the proper flow of operations and documented the activities while the operator performed the changeover. Table 1 presents workshop participants, their functions in the Enterprise $\mathrm{X}$ and the tasks assigned during the changeover.

Table 1. Tasks for each employee during changeover

\begin{tabular}{|l|l|l|l|}
\hline Name & Function & & Function during changeover \\
\hline Marek & Production technician & & Flash Light, video recording \\
\hline Anna & Lean coordinator & & $\begin{array}{l}\text { Workshop moderation, } \\
\text { spaghetti diagram }\end{array}$ \\
\hline Marcin & Lean coordinator & & $\begin{array}{l}\text { Recording and measurement } \\
\text { of activities }\end{array}$ \\
\hline Jan & Process technology & & Flash Light, video recording \\
\hline Krystian & Operator & & Performing changeover \\
\hline Kamil & Shift manager & & Observation, photographs \\
\hline
\end{tabular}

Source: author's own elaboration based on the materials from the enterprise $X$

Before the changeover, the training for the whole team was organized by the previously trained workshop moderator. The SMED problems and dedicated tasks were explained in detail. 


\section{Type of changeover}

Changeover concerns the change from the product A and $\mathrm{B}$. It is important that the changeover did not concern the machine equipped in cogwheels, which could significantly extend the changeover time. The machine chosen for changeover is a multiple-unwinder machine equipped in 4 unwinders. In this case, the number of unwinders plays a substantial role since the employee changed from three to two unwinders, which means that number 3 was skipped during the changeover and the semi-finished product was removed from this unwinder when the machine was operating.

\section{Changeover procedure}

Before the changeover was started, the participants were asked to attempt to perform their work in a standard manner as it is done every day. However, the conditions during the changeover were substantially different from those observed every day. Normal working conditions of the operator of such machines consists in operating several machines at the same time. During the changeover, the operator operated only one machine. This activity was purposeful due to the fact that the attempts on the stranding machines were performed for the first time.

The effects of activities of the team were collected in an unstructured manner. Study participants performed the tasks loyally and with due diligence, which allowed for optimization of the changeover by individual team members.

\section{Flash Light}

The tasks of production technician and process technologist included identification of the chances for the improvements in the changeover and indication of the areas that can be improved. The essence of this step was writing down all the ideas. The outcome of this work was 11 ideas which were than verified and added to the action plan. The ideas collected using the Flash Light methodology are presented in Table 2.

Table 12.2 contains a list of ideas generated by the team responsible for Flash Light. The authors of all the ideas were production technician and process technologist. 
Table 2. Flash Light obtained during the workshop

\begin{tabular}{|l|l|l|}
\hline No. & Topic & Author \\
\hline $\mathbf{1}$ & Lift - greater lifting/lowering speed & technician and technologist \\
\hline $\mathbf{2}$ & $\begin{array}{l}\text { Preparation of the bobbin before the machine is } \\
\text { stopped }\end{array}$ & technician and technologist \\
\hline $\mathbf{3}$ & Prescription on the machine & technician and technologist \\
\hline $\mathbf{4}$ & Transfer of material (streaks), dry run & technician and technologist \\
\hline $\mathbf{5}$ & Reducer used to reduce pressure on all unwinders & technician and technologist \\
\hline $\mathbf{6}$ & Ruler on the machine & technician and technologist \\
\hline $\mathbf{7}$ & Marking of the disc diameter & technician and technologist \\
\hline $\mathbf{8}$ & Position of pressure reducer & technician and technologist \\
\hline $\mathbf{9}$ & Searching the surname in the system: control area & technician and technologist \\
\hline $\mathbf{1 0}$ & $\begin{array}{l}\text { Conversion factor for the strand pitch - change of } \\
\text { the device - real value }\end{array}$ & technician and technologist \\
\hline $\mathbf{1 1}$ & Completion of the checklist after machine startup & technician and technologist \\
\hline
\end{tabular}

Source: author's own elaboration based on the materials from the enterprise $X$

\subsection{Action plan}

The action plan was prepared during the previous changeover. This led to preparation of the list of 9 items of which 3 were implemented, 4 were cancelled due to the lack of feasibility and two are still in progress. Table 3 presents a complete list for the action plan, containing the number, topic, data, owner and status.

Table 3. Action plan

\begin{tabular}{|c|l|c|}
\hline No. & \multicolumn{1}{|c|}{ Topic } & Status \\
\hline $\mathbf{1}$ & Preparation of the bobbin before the machine is stopped & Closed \\
\hline $\mathbf{2}$ & Transfer of material (streaks), dry run & Closed \\
\hline $\mathbf{3}$ & Reducer used to reduce pressure on all unwinders & Cancelled \\
\hline $\mathbf{5}$ & Ruler on the machine & Closed \\
\hline $\mathbf{6}$ & Marking of the disc diameter & Cancelled \\
\hline $\mathbf{7}$ & Position of pressure reducer & Cancelled \\
\hline $\mathbf{8}$ & $\begin{array}{l}\text { Searching for the name in the system- control area - searching } \\
\text { according to the first letter }\end{array}$ & In progress \\
\hline $\mathbf{9}$ & Completion of the checklist after machine startup & Cancelled \\
\hline
\end{tabular}

Source: author's own elaboration based on the materials from the enterprise $X$ 
Table 3 presents the action plan. Justification for the cancelled items is as follows:

1) Changed machine design. Lack of consent from the Maintenance Department. Lack of opportunities for implementation.

2) Ambiguity and lack of reproducibility of disc marking. Lack of opportunities for implementation.

3) Changed machine design. Lack of consent from the Maintenance Department. Lack of opportunities for implementation.

4) Inconsistency with current quality procedures. Lack of opportunities for implementation.

\section{Development of the initial standard of changeover}

The film recorded and the activities written by the coordinator allowed for creation of a line with individual operations.

Activities, which were aimed to reduce changeover time included:

- change of the order of selected activities,

- change of the internal into external activities,

- combination of several activities into one.

Line with individual activities contributed to the creation of the initial changeover standard. The order of activities was developed by the interdisciplinary team and the effects of their work is a special instruction.

Next items were the elements of changeover including the external and internal activities.

\section{Results}

Changeover time was reduced by $39 \%$. The reduction was substantially better than the assumed outcome. These differences can be explained by the fact that this was the first changeover in this area. Its evaluation was intuitive and subjective. Therefore, the team assumed the safety margin for the results obtained.

The changeover is summarized by the Table 4 . It contains the results obtained and the assumed goal. For comparison purposes, the table contains the values before implementation of SMED.

Table 4. Comparison of the expected and obtained effects during the workshop

\begin{tabular}{|l|l|l|}
\hline & Time[min] & Distance covered [m] \\
\hline $\begin{array}{l}\text { State before the SMED } \\
\text { implementation }\end{array}$ & 56 & 892.5 \\
\hline Purpose & 48 & 700 \\
\hline
\end{tabular}




\begin{tabular}{|l|l|l|}
\hline Current state & 34 & 373 \\
\hline \multicolumn{2}{|l|}{} \\
\hline Reduction assumed & $14 \%$ & $22 \%$ \\
\hline Reduction obtained & $39 \%$ & $58 \%$ \\
\hline
\end{tabular}

Source: author's own elaboration based on the materials from the enterprise

Data presented in Table 4 are not only the synthetic summary of the results. Analysis concerned the assumed and obtained reduction of the time of changeover and distance covered. In the case of time reduction, we assumed the decline by $14 \%$. The result obtained was $36 \%$. The distance covered was expected to be reduced by $22 \%$. The result obtained was 58\%. In order to ensure the reproducibility of the result, a standard was developed, named changeover instruction No. LP051_003. The standard was verified and the result obtained was found to be satisfactory. Within the described actions, we also organized the promotional campaign for other employees. The campaign consisted in organization of SMED promotional meetings and banners that explained the benefits of the SMED method to the employees.

The examples of the contents of the banners are:

- SMED means less walking during work,

- SMED means better exchange of semi-finished products,

- SMED means tools waiting at specific places,

- SMED means your machine more available to production.

Other element of the project was employee training. All the employees who operated the machine on the instruction developed during the workshop had an training. The follow-up audit was scheduled for July 2017.

\section{Conclusions}

Competitiveness in the free market is fundamental. It is competition that plays increasingly critical role in the finances in enterprises. Nowadays, the enterprises area challenged with reaching higher and higher performance, while chances to reach the expected outcomes start to decrease at a specific moment. The question arises concerning the cost reduction: have all the opportunities connected with the reduction been depleted? A number of enterprises respond to this challenge with implementation of lean management systems. This concept integrates the elimination of unwanted activities which do not add value and only generate costs. Therefore, the enterprises, due to the costs and production flexibility, are implementing SMED since reduction of the changeover time is connected with, among other things, the improvement in production indices and, consequently, economic effects. 
Based on the theoretical investigations, this study presents the attempt to use the SMED methodology in the production enterprise $X$.

The measurable effect of the examinations was reduction of the changeover time by $39 \%$. The design team assumed the achievement of a substantially poorer outcome. The aim was to reduce the changeover time from 56 minutes to 48 minutes, which, calculated in percentage terms, meant a $14 \%$ reduction. Therefore, the actual result was much beyond the team's expectation, which is presented in Table 4. A surprising fact for the research group was the number of metres to be covered by the employee during a single changeover. This value was about one kilometre. In extreme cases, the operator had to cover this distance even 5 to 6 times. It should be noted that the mean number of changeovers per one employee is three per shift. The focus of this study was on one employee, who operated one machine at a time. This is not entirely consistent with actual conditions, since in the system of work used in the enterprise, employees operate several and even more than ten machines simultaneously. The operator is unable to be focused exclusively on the changeover of one machine since they supervise production performed on other machines. This is connected with the necessity to check the correctness of the process and to respond to problems with the process, such as incorrect positioning of the product on the bobbin, discoloration, loose wires or breakage. Therefore, the question arises whether the obtained results are reliable and practicable since the time was evaluated in the case of operation of only a single machine.

However, this question can be verified after the follow-up audit, which is planned to be performed in July 2017.

\section{Bibliography}

1. CoImbra E. A. 2009. Total Flow Management. Achieving Excellence with Kaizen and Lean Supply Chains. Swizerland.

2. Косн T. 2011. Materiały z konferencji: E-narzędzia i technologie generatywne jako szybka ścieżka do innowacji, Jak stosować metody Lean manufacturing (Oszczędnego Wytwarzania) do wprowadzania innowacji. Warsaw.

3. ShIngo S. 1989. A Study of the Toyota Production System. Productivity Press. New York.

4. SzATKOWSKI K. 2014. Nowoczesne zarządzanie produkcją. Ujęcie procesowe. PWN. Warsaw.

5. http://lean.org.pl/smed-czyli-skracanie-czasow-przezbrojen-maszyn-i-urzadzen/ 